\title{
ESTUDIO LÉXICO DE UN DOCUMENTO MEDIEVAL CASTELLANO: ORDENAMIENTO DE TRABAJOS Y PRECIOS
}

Josefa M.a Mendoza Abreu

El documento que estudiamos se encuentra en la rica colección diplomática que posee el Archivo Municipal del Concejo de Écija, parte de la cual fue transcrita por la profesora M. Josefa Sanz ${ }^{1}$; entre estos documentos se halla el que hemos elegido para su estudio. Se trata de un Ordenamiento de Cortes, de los emitidos por Pedro I en las Cortes de Valladolid de 1351, regulando los precios y salarios que han de regir en los diferentes lugares del reino, después de la gran peste que había asolado el territorio nacional tres años antes y que había diezmado considerablemente su población y su riqueza. Concretamente en éste se ordenan los trabajos y precios que han de regir en el arzobispado de Sevilla y los obispados de Cádiz y Córdoba, y fue dado a la ciudad de Écija ${ }^{2}$.

Pero, como decía, este es uno más de los documentos correspondientes a esas Cortes de Valladolid, y existen, similares a él, cinco más, cuatro de los cuales fueron publicados en los Cuadernos de Cortes $^{3}$, correspondientes a los arzobispados de Toledo; Sevilla; obispados de León, Oviedo; y a los territorios de Burgos,

1 Ma. Josefa Sanz Fuentes, Colección Diplomática del Concejo de Écija, Sevilla, 1976 (Tesis doctoral inédita).

2 Desde el punto de vista diplomático es un documento original, fechado en Valladolid el 2-X-1351; se halla en la carpeta II, n. 32 del citado Archivo, escrito en un cuadernillo de papel con seis hojas tamaño folio más una guarda, bien conservada en general, aunque el último folio está roto por la mitad.

3 Cortes de los antiguos reinos de León y de Castilla, Madrid, 1863, t. II, págs. 75-124. 
Castrojeriz, etc ${ }^{4}$. Un quinto documento ha sido publicado posteriormente por Juan Torres Fontes, correspondiente a Murcia 5 .

Los seis documentos guardan una estrecha relación, al tratarse del mismo tema. Sin embargo existen entre ellos «diferencias notables en los precios de las cosas y de los jornales», como señalan los autores de Cuadernos de $\operatorname{Cortes}^{6}$, e incluso en los distintos tipos de trabajos ${ }^{7}$. Pero además, desde el punto de vista que a nosotros más directamente nos interesa, existen también algunas diferencias lingüísticas, unas en el plano fonético-fonológico (Así, por ejemplo, en el documento correspondiente a los obispados de León, Oviedo, etc. son constantes los usos de la palatal «ll» / 1 / sobre todo en posición inicial, en palabras en las que en los demás documentos aparece generalmente la alveolar «l»/1/: llisiones (pág. 103, § 1) frente a lissiones (pág. 76, § 1) e incluso el caso inverso, por ultracorrección: sielas (pág. 108, § 23) por siellas). En el plano léxico se observan también diferencias, de las cuales comentaremos más adelante (en el estudio léxico) sólo aquellas que estén directamente relacionadas con este documento. Estas diferencias, en mi opinión, tienen dos razones fundamentales, una determinada por los distintos lugares del reino a los que iban dirigidos los Ordenamientos, otra, que enlaza directamente con la anterior, viene condicionada probablemente por la procedencia de los distintos escribanos que intervinieron en la elaboración de cada uno de los documentos. Torres Fontes señala que el Ordenamiento al reino de Murcia fue otorgado en el mismo día que el primero de los cuatro que aparecen en Cortes, el correspondiente a Toledo y Cuenca, pero que en términos generales el concedido a la región murciana guarda mayor afinidad con el promulgado en fecha posterior para el arzobispado de Sevilla lo que, según él, indicaría que en la confección de este último, y, por tanto, del nuestro, se tuvo presente el redactado anteriormente para el reino de Murcia ${ }^{8}$. Sin embargo esta afirmación no se puede aceptar sin reservas, pues tanto el documento del arzobispado de Sevilla correspondiente a Niebla, como el correspondiente a Écija contienen un mayor número de artículos, y muchos de ellos diferentes. Por ello es más lógico pensar que existiera un primer original, e incluso cuatro primeros originales, correspondientes a cada una de las cuatro notarías mayores de aquella época (Toledo, Andalucía, León y Castilla), y de ellos, con algunas modificaciones, se irían copiando los demás. De esta manera se explicaría más fácilmente tanto los artículos que se repiten prácticamente igual en todos los Ordenamientos, como la identidad en cuanto al contenido, e incluso las pequeñas variantes entre el de Niebla

4 Publicados, respectivamente, los docs. dados a las villas de Madrid (28-IX), Niebla (12-X), León (20-X), y una copia del siglo XV del ejemplar de Valladolid.

5 Juan Torres Fontes, Anuario de Historia del Derecho Español, t. XXXI, Madrid, 1961, págs. 281-292.

6 Pág. 75, nota 1.

7 Que, como muy acertadamente indica Torres Fontes, refiriéndose al de Murcia, puede interpretarse en el sentido de que los oficios recogidos en sus artículos y no repetidos en los otros ordenamientos eran exclusivos o preponderantes en cada región económica en que se dividía el reino castellano: op. cit., págs. 283-284.

8 Op. cit., pág. 283. 
y el de Écija, que han tenido que ser copiados de un original común, por razones que veremos en el estudio de las distintas voces.

En cuanto al estudio del léxico del documento astigitano, es preciso señalar que, dada la abundancia de términos recogidos, sólo vamos a ocuparnos de aquellos de los que, de alguna manera, el resultado de la investigación pueda aportar datos para su mejor conocimiento, ya sea en relación con su estructura formal, con su significación, o con la fecha de su primera documentación.

\section{açicaladores}

«... e ferreros e tundidores e pelligeros e freneros e açicaladores e orebzos...» (fol. 5v., lins. 6-7).

El DRAE, s.v. acicalador 1 recoge «Que acicala», y s.v. acicalar 1 «Limpiar, alisar, bruñir, principalmente las armas blancas». Es decir, el mismo significado con que aparece en este texto y en general en todos los textos castellanos medievales. Ahora bien, la forma más común en esta época es con -e-, açecalar, y damos la forma verbal porque en ninguno de los vocabularios y glosarios medievales consultados aparece açecalador. Nebrija incluye las formas açicalar, açicalado, açicaladura en su Voc. Esp.-Lat. ${ }^{9}$, pero estas mismas formas aparecen con -e- en el Voc. Lat.-Esp. ${ }^{10}$. Este hecho lo señalan los autores del $D E C H^{11}$, quienes añaden, además, que las formas con - $i$ - aparecen como variantes en el Cancionero de Romances de 1550 y no predominan hasta el siglo XVII. «En vista de esta fecha tardía - dicen - es posible que la forma con - $i$ - sea debida a alguna contaminación, quizá la de cica 'bolsa' por los gastos que ocasiona el acicalarse». Pero esta contaminación, además de no resolver el problema fonético de evolución planteado por Neuvonen (del cambio de «a» árabe a «e»: saqual > cecalar), como ellos mismos argumentan, plantea otro problema y es que la primera documentación que aparece en el DECH de cica (s.v. cicatero) es de 1609, por lo que este término mal habría podido influir en las formas con - $i$ - recogidas por Nebrija y menos en este caso. Por lo que quizás habría que pensar en la influencia de otra palabra, o bien admitir como étimo el infinitivo árabe siqâl, propuesto también por los autores de DECH. Por otro lado, García de Diego, en el DECH, s.v. zaicala, hace derivar el término del sustantivo árabe sical 'pulimento'; mientras que Dozy-Engelmann, Glossaire, s.v. acicalar piensan que el étimo es el verbo çaica$l a$, y que el diptongo ai $>\mathrm{i}$, (como se observa en algunas palabras del bereber) ${ }^{12}$.

9 Nebrija, E. A. de, Vocabulario Español-Latino, ed. Facsímil por la Real Academia Española, Madrid, 1951.

10 Nebrija, E.A. de, Diccionario Latino-Español (ed. facs.), Estudio de G. Colón y A. J. Soberanas, Barcelona, Puvill, 1979.

11 Corominas, J. y Pascual, J. A., Diccionario Crítico Etimológico Castellano e Hispánico, Madrid, Gredos, 1980 y ss. (citado DECH).

12 Dozy, R. y Engelmann, W. H., Glossaire des mots espagnols et portugais derivés de l'arabe, Amsterdam, 1915 (citado Glossaire). 


\section{albannies}

«mando que todos los carpenteros e albannies e tapiadores e peones e obreros...» (fol. 1v., lins. 1-2).

Derivado del árabe 'banna' (DECH, s.v. albañil). Es la forma general que aparece en este documento y también la más generalizada en los otros de Cortes $^{13}$. Corominas y Pascual dicen que albañil es un arabismo tardío, pues aparte de su primera documentación albani en las Cortes de Jerez de 1268 y el plural albannies en la Gn. Conquista de Ultramar, no vuelve a haber dato alguno de albañil o sus variantes hasta 1400 (Glos. de Toledo) y algunos textos del siglo XV.

alinpiar

Et por açecalar e alinpiar un bacinete un maravedí. Et por açecalar e alinpiar una capellina quinze dineros» (fol. 3v., lins. 22-24).

Corominas y Pascual, s.v. limpio, documentan limpiar en Apal y alimpiar en Nebrija, haciéndolo derivar de un latín tardío LIMPIDARE. Pero alimpiar es la forma general que aparece en estos documentos de Cortes. Cejador, Voc. Med., documenta alimpiar en J. Ruiz, 792 (la forma, registrada en la edición de Corominas del Libro de Buen Amor es alimpiat) y en el mismo DECH, s.v. zapato aparece un fragmento de Sta. M. ${ }^{a}$ Egipciaca, 809 en el que se lee: "por alimpiarse de sus pecados / non calçava çapatos». Todas estas formas con $a$-inicial parecen indicar que sería alimpiar la primitiva y que, consiguientemente el étimo propuesto por García de Diego, ELIMPIDARE (DEEH, s.v.) ${ }^{14}$, con cambio de vocal inicial átona (explicable quizás por falsa confusión de prefijos, o para facilitar la conservación de la vocal inicial silábica) sería más acertado.

asegador

«Et al asegador que le dan por su jornal de todo el día tres maravedis» (fols. $2 \mathrm{v}$. , lins. 3-4).

En el DECH, s.v. segar, se documenta segador en APal 277d, Nebrija. En el documento de Niebla similar a éste aparece aserrador, lo que parece ser una mala lectura, pues se está regulando los salarios de los hombres y las faenas del campo. Pero tanto segador, como su variante con $a$ - no parece que sean aún muy frecuentes, pues en el ordenamiento de Toledo aparece «que den acada obrero el día que ssegare...» (pág. 79, § 9); en el de León también aparece algo similar «et den al obrero que ssegare con foz cada día... et den al obrero que ssegäre con padana (¿guadaña?)...» (pág. 105, § 7); mientras que en el de Burgos aparece guadannero (pág. 116, § 17).

13 En el de Burgos aparece Albeniques (pág. 113, § 3) y la forma murciana es albannis (pág. 291, $\S 27)$.

14 García de Diego, V., Diccionario Etimológico Español e Hispánico, Madrid, Espasa-Calpe, 1985 (citado DEEH). 


\section{caporotadas}

«echar la penna vera [...] a los mantos de las duennas e de las otras personas por dos maravedis. Et a los tabardos e caporotadas de pena vera o blanca por dos maravedis e medio» (fol. 45, lins. 26-28).

En el ordenamiento de Toledo y el de Niebla aparece caperotadas (pág. 86, $\S 31$ y pág. $98 \S 31$, respectivamente), en el de León capirotadas (pág. 107, § 17) y en el de Murcia capirotados (pág. 289, § 18).

Parece ser un tipo de vestidura similar a las capas y tabardos, o más concretamente un capirote más amplio. No creo que sea exactamente igual al capirote, pues en todos los documentos aparecen diferenciados.

El DRAE, s.v. capirotada 1 recoge «aderezo hecho con hierbas, huevos, ajos y otros adherentes para cubrir y rebozar con él otros manjares». Similares son los significados que aparecen también en Autoridades, Covarr y DECH, s.v. capa. Nebrija, en su Voc. Esp.-Lat. dice «capirotada de ajos e queso». Es decir, en todos se hace referencia a un tipo de aderezo de comidas o a la comida misma. Pero además el DRAE, s.v. capirotado, da, señala «adj. Blas. Dícese de cualquiera figura humana o animal con caperuza, singularmente las aves de caza con el capirote puesto», que indudablemente estaría más próximo a nuestro significado que el anterior, por la relación con capirote.

\section{çerrada}

«Et echen el par de las suelas de la çerrada por diez e ocho dineros et el par de las suelas de la mediana por treze dineros» (fol. 3r, lins. 25-26).

Término que encontramos con la misma significación recogida por Autoridades, s.v. «la parte de piel que corresponde al cerro del buey o vaca, que es la más gruesa y fuerte de toda ella», donde aparece un ejemplo de La Nueva Recopilación de las Leyes del Reino (s. XVI) ${ }^{15}$. Igual significado encontramos en el $D R A E$, s.v. cerrada 1 «La parte de la piel del animal que corresponde al cerro o lomo. El $D E C H$ lo documenta, sin fecha, también con este mismo significado.

\section{costureros}

«ayan los costureros por coser e solar los çapatos de omme e de muger...» (fol. 3r., lins. 8-9).

El significado 'hombres que cosen zapatos' aparece suficientemente claro. Sin embargo no es un término recogido en los glosarios y vocabularios medievales. Nebrija documenta la forma femenina costurera. farcinator. icis. en su Voc. Esp.-Lat. Tampoco Covarr ${ }^{16}$ ni Autoridades lo recogen. El DRAE, s.v. costu-

15 Real Academia Española, Diccionario de Autoridades, Edición facsímil, Madrid, Gredos, 1984 (citado Autoridades).

16 S. de Covarrubias, Tesoro de la lengua castellana o española, Madrid, Turner, 1979 (Citado Covarr). 
rero 3 dice «ant. sastre». Sin embargo en los Fueros Aragoneses de la época también Tilander da ejemplos con este mismo significado, además de otros en los que aparece con el de 'sastre ${ }^{6}{ }^{17}$, tal como señala la Academia.

\section{çuecos}

«Et por el par de los çuecos dorados seys maravedís; et por el par de los çuecos de tres çintas cinco maravedís; et por el par de los çuecos de una çinta quatro maravedís. Et por el par de çapatos de una çinta dos maravedís» (fol. 3r., lins. 21-23).

Similar en los ordenamientos de Niebla, León y Burgos.

El DCELC, s.v. zueco, lo define como «especie de pantufla empleada por las mujeres y los comediantes», 1 . doc. 1475 , G. de Segovia ${ }^{18}$. Y este es el significado más generalizado que se recoge en la mayoría de los vocabularios medievales y posteriores. Pero Corominas señala también que en otras lenguas como el portugués, se recoge «çocos o çoques como una variante de zueco bueno», y da un ejemplo de L. de Vasconcelos, Opúsc. II, 343-4. Apal., s.v. çueco dice: '43d 'chinela', 53d 'calçado', pero además añade «los çuecos no se ligan como las calças mas metense en los pies» ${ }^{19}$, lo que parece contradecir los distintos tipos de zuecos de varias cintas que aparecen en nuestro texto, a menos que esas cintas fueran como adornos, lo que parece extraño, sobre todo en el caso de los zapatos.

Nebrija, s.v. çueco dice: «calçado de cierta forma, soccus, i», sin dar más detalles.

Pero que zueco designa también un tipo de zapato «bueno», al igual que en portugués çocos o çoques, y con más usos de los que aparecen generalmente recogidos, siguiendo los latinos, se observa, además de en el texto citado, al final del artículo, en el que se dice: «Et a todo esto dorado que echen tales suelas e atan buenas commo agora usan al echar» (fol. 3r., lins. 23-24).

enargentado, -da, $-\mathrm{S}$

«Et por el par de las estriberas doradas... Et por el par de las estriberas enargentadas mulares...» (fol. 5r., lins. 5-6).

«Et por el par de las espuelas argentadas seys maravedís. Et por el freno argentado de perlados... Et por el par de las estriberas enargentadas (fol. 4v., lins. 30-31). Et por el preytal enargentado diez maravedís. Et (...) los otros frenos enargentados... (fol. 5r., lins. 1-2).

Variantes utilizadas junto con argentado (que son las más frecuentes en la época), $-a$, como puede verse en el texto, e indistintamente, sin ninguna explica-

17 G. Tilander «Fueros aragoneses desconocidos, promulgados a consecuencia de la gran peste de 1348», R.F.E. XXII, 1935, págs. 1-13 y 113-152.

18 Corominas, J., Diccionario Crítico Etimológico de la Lengua Castellana, Madrid, Gredos, 1976 (citado DCELC).

19 A. de Palencia, Universal Vocabulario en Latín y en Romance. Reproducción facsimilar de la edición de Sevilla, 1490; Comisión Permanente de la Asociación de Academias de la Lengua Española, Madrid, 1967. 
ción especial que no sea la tendencia a formar derivados con prefijos sin añadir ningún matiz significativo al vocablo, como vamos a ver en las siguientes voces estudiadas.

Sólo documentamos estas formas en estos textos de Cortes. En los Fueros aragoneses aparece siempre la forma sin prefijo.

\section{enplatados}

«Et por el par de los çapatos enplatados para omne cuatro maravedís» (fol. 3r., lins. 21-22).

En lugar de argentado o enargentado, que son los términos más usuales, en este caso encontramos, con el mismo significado, enplatados, utilizando el mismo sistema de derivación, sobre la base plata. Esta forma se repite además en los cuatro documentos de Cortes (pág. 83, § 21; pág. 96, § 24; pág. 105, § 10; pág. $117, \S 25$, respectivamente); sin embargo no aparece recogida en los estudios consultados.

\section{entretallar - entretalladura}

«et por la capa o çulame de omme çenzillo... et sy lo quisiere entretallar que se abenga el que asy lo quisiere entretallar con el alfayate en razon de la entretalladura (fol. 4r., lins. 7-9).

De forma similar en los otros documentos de Cortes. Al tratarse de una capa no es fácil pensar que entretallar tenga el significado dado por Covarr., s.v. entallar «dar buen talle y garbo a alguna cosa que venga justa». Cejador, Voc. Med., s.v. entretallar sólo da un ejemplo de Sta. M. ${ }^{a}$ Egipciaca 242 «çapatas de cordouan entretalladas», pero no aporta ningún significado ${ }^{20}$. Referido al calzado aparece también el término entallar en las Cortes de 1252 de Alfonso X «Et çapatos prietos de cabrito entallados... et de cordoban entallados...» ${ }^{21}$. El DRAE, s.v. entretallar de las siguientes acepciones «Trabajar una cosa a media talla o bajo relieve // Grabar, esculpir // Sacar y cortar varios pedazos en una tela, haciendo en ella calados o recortados; como en ciertos bordados, sobrepuestos, etc.». Es esta tercera acepción la que parece coincidir con el significado que tendría entretallar en este texto. El consiguiente significado de entretalladura aparece en el DRAE s.v. entretallamiento, en su tercera acepción.

\section{espadador}

«den al espadador por su jorrnal por la arroua de lino dos maravedís e medio» (fol. 2v., lín. 8).

Igual en Niebla (pág. 94, § 14).

20 Cejador y Franca, J., Vocabulario Medieval Castellano, New York, 1968 (citado Voc. Med.).

21 A. Ballesteros, «Las Cortes de 1252» en Anales de la Junta para ampliación de estudios e investigaciones científicas, t. III, Madrid, 1911, pág. 127. 
En el DECH s.v. espada, se señala que espadar aparece en 1463 en los fueros aragoneses $(V . R o m . \mathrm{X}, 147)$ y en Nebrija «espadar lino: carmino linum», derivado de espada en el sentido etimológico de 'pala de artesano' o 'espátula'. La forma espadador aparece sin fecha, pero recoge espadadero en Apal. 17d.

\section{çerrajas - cerradura}

«Et den las çerrajas para las puertas con su çerradura cada una por dos maravedís e medio» (fol. 3v., lin. 13).

Generalmente se ha venido entendiendo que cerraja y cerradura tenían el mismo significado. Sin embargo en este caso hay evidentemente unas diferencias. A. Castro, que recoge el término cerraja en los Aranceles de Aduanas ${ }^{22}$, entre otros objetos manufacturados de hierro, llama la atención sobre el uso del término en los Docs. de Cortes, concretamente en el del Ordenamiento de Sevilla (Niebla), similar a éste, que es el único en el que también aparece, y dice que «parece que cerradura se refiere aquí al pestillo o a lo que sirve directamente para el cierre, y cerraja al objeto en conjunto». Y añade, por lo demás, los numerosos ejemplos de cerradura que tengo no permiten aclarar la duda.

Nebrija, Voc. Esp.-Lat. s.v. cerrojo, da «cerradura, sera -ae». Por lo que bien puede pensarse que en este caso çerradura equivale al actual 'cerrojo', mientras que çerraja sería 'cerradura'.

\section{formigeros}

Et a los fornigeros para traer lenna para los fornos...» (fol. 2v., lin. 29).

En el Ordenamiento de Niebla aparece fornigueros (pág. 95, § 19). Término que recogemos con la misma significación que aparece en el DRAE s.v. forniguero 1: m. ant. «encargado de un horno». Sin embargo la forma usual desde el principio y documentada desde 1170 es fornero-hornero según el $D E C H$, s.v. horno. Efectivamente tanto APal. como Nebrija, Covarr. o Autoridades sólo recogen hornero. El $D E C H$ recoge además la variante hornijero, aunque sin fecha, que es la forma evolucionada de la que aquí documentamos.

gramayas

Et den el par de çapatos de correa çerbienos por seys maravedís. Et el par de las gramayas de bezerro por tres maravedís» (fol. 3r., lins. 27-28).

Igual en el ordenamiento de Toledo (pág. 82, § 20) y en el de Niebla (pág. $96, \S 25)$.

Casi todos los estudios que recogen el término, generalmente bajo la forma gramalla, coinciden en afirmar que es un «tipo de vestidura larga hasta los pies, empleada por altos cargos de la administración, generalmente en la Corona de

22 A. Castro, «Unos aranceles de aduanas del siglo XIII», R.F.E., VIII, 1921, págs. 1-29 y 325-356; t. IX, págs. 266-276 y 5. X, págs. 113-136. 
Aragón» (Así el DECH, DRAE, Autoridades, Covarr., Borao ${ }^{23}$, Andolz ${ }^{24}$, $D C V B^{25}$ y otros). De etimología incierta, su primera documentación, según el $D E C H$, se halla en los invent. arag. de 1397 y 1406. Alcover y Moll documentan la variante ortográfica antigua gramaya a. $1294{ }^{26}$.

C. Bernis Madrazo señala que desde principios del siglo XIV se cita a menudo en los textos la gramasia pluvial usada generalmente en los lutos, y la gramalla vestida con el mismo fin, y opina que la gramasia o gramalla era lo mismo que la garnacha ${ }^{27}$.

Pues bien en este caso, aún coincidiendo con la variante fonética catalana antigua, debe tratarse de otro término, que habría que hacerlo derivar de grama o gramal. (En el DECH, s.v. gramalla, se da como posible étimo grammatica). En el $D E E H$, s.v. grama aparece el significado de «fibra del cáñamo, en nav.»; Andolz, s.v. gramalla 2 «agramiza, despojos del cáñamo agramado». Por lo que muy bien podría ser que del uso del cáñamo en las suelas o como cinta para atar los zapatos pudiera pasar a designar el nombre de los mismos.

\section{Jormal - Jornaleros}

«... demandauan tan grandes preçios e soldadas e jornales...» (fol. 1r., lins. 13-14). «...que den por su jornal al omme para vinar...» (fol. 2r., lin 9 y passim). «... e peones et obreros e obreras et jorrnaleros e los otros omes e menestrales...» (fol. 1v., lins. 1-2).

Igual en los otros documentos de Cortes.

El DECH, s.v. jornada documenta jornal h. 1400 en Glos. del Escorial, APal., Nebr. y jornaleros en Nebrija. También G. Colón documenta jornal en la misma época ${ }^{28}$.

\section{Jubetes}

«Et a los maestros que ovieren de fazer ganbaxes e jubetes de armas denles por los fazer en esta manera... por fazer el jubete para arma ocho maravedís... (fol. 4r., lins. 21-23).

También aparece en los otros documentos de Cortes.

El $D R A E$, s.v. recoge «coleto cubierto de malla de hierro que usaron los soldados españoles hasta fines del siglo XV». El DEEH, s.v. chubba (ár.) dice jubete 'coleto', deriv. de juba. Pero parece que al dejar de utilizarse el objeto debió de ir perdiéndose también el vocablo, pues tanto Covarr. como Autoridades no hacen mención a él, aunque sí aparece en ambos jubeteria «la tienda en que se

23 Borao, J., Disccionario de voces aragonesas Zaragoza, 1980.

24 Andolz, R., Diccionario aragonés, Zaragoza, 1977.

25 A. Alcocer y F. Moll, Dicionari Catalá, Valenciá, Balear, Barcelona, 1969 (citado DCVB).

26 DCVB, s.v. gramalla.

27 C. Bernis Madrazo, Indumentaria Medieval Española, Madrid, C.S.I.C., 1955, pág. 34.

28 G. Colón, «Elementos constitutivos del español: occitanismos», en Enciclopedia Lingüistica Hispánica, t. II, pág. 179. 
venden jubones y otras ropas semejantes» y jubetero «el que hace, compone y adereza jubones y otras ropas», que indudablemente serían derivados de jubete y no de jubón. Nebrija recoge jubón «vestido nuevo» y jubetero «sastre que los hace». El DECH, s.v. jubón, da como derivado jubete y hace referencia al significado de la Academia.

\section{linnuelo}

«por coser e solar los çapatos de omme e de muger de linnuelo dos dineros e medio; e sy los cosiere con correa dos dineros» (fol. 3r., lins. 9-10).

En el Ordenamiento de Niebla, el único en que aparece, se lee luniello (pág. $95, \S 23)$, lo que parece un error, probablemente de transcripción.

El DRAE, s.v. liñuelo recoge «cada cabo o ramal de las cuerdas o trenzas». El DEEH, s.v. lineola, «liñuelo 'ramal' cast. DRAE; liñolo 'cabo, hebra', ast. occ.; liñol 'id. gall'». Cejador, Voc. Med., s.v. linuelo, da el significado de 'sur$\mathrm{co}^{\prime}$ en un texto del siglo XV «labraron esos carrillos de tan ásperos linuelos». Pero en este caso el significado es claramente el de 'cabo, hebras de lino'. En el $\mathrm{DECH}$, s.v. línea, aparece como derivado, sin fecha ni significado.

\section{margomaduras}

«Et por la piel e capuz syn margomaduras e syn forraduras un maravedí; et sy fuere con margomaduras o con forraduras que le den quinze dineros (fol. 4r., lins. 9-10).

El DRAE, s.v. margomar señala: «ant. labrar una tela o piel». Autoridades, s.v. «lo mismo que bordar. Es voz anticuada» y da un ejemplo de J. de Mena. También Nebrija, Voc. Esp-Lat., s.v., lo da como verbo anticuado y traduce plumo, -as. El derivado margomaduras aparece recogido en el Glossaire de Dozy y Engelmann, quienes señalan, s.v. morcummargomar (broder) que de margomar se ha formado margomadura, que se busca en vano en los diccionarios, pero que se encuentra en Cortes del siglo XIV con el significado de bordure, y citan un texto similar a éste, recogido de uno de los documentos de estas Cortes. Sin embargo, C. Bernis Madrazo recoge el término con el significado de «guarniciones rectangulares en la parte alta de las mangas, que adornaban los trajes de los hombres, ya en el s. XIII» ${ }^{29}$. En el DECH, s.v. recamar, aparece margomar, pero no margomadura.

\section{plegaduras}

«Et estos escudos e adargas que los vendan e den con sus guarnimientos e plegaduras (fol. 4v., lins. 23-24)

Esta voz se repite así o en su variante pregaduras en todos los documentos de Cortes. Parece que hace referencia a los clavos y material de hierro utilizado en los escudos. 
El DECH, s.v. plegar recoger un ejemplo de principios del siglo XIV en el que este verbo aparece con el significado de 'clavar ${ }^{6}$ : $A$ Ay, Señor! Commo fuestes vos traydo de los judios descreidos, et ferido et mal menado, et en la vera cruz plegado, et escopido» (Cuiento de Otas).

Tanto Autoridades como el DRAE, s.v. pregar, recoger también este verbo como anticuado, con el significado de 'clavar, afianzar'.

En este sentido parece que se podría interpretar también el sustantivo plegadura recogido por Nebrija, Voc. Lat-Esp., que traduce por plicatura, ae y plicatio, -onis.

Un ejemplo donde se observa también este significado lo tenemos en el ordenamiento de Burgos: «Et a los ferreros denles por echar la libra del fierro alas açadas e alas otras... et por la libra de la calçadura menuda çinco dineros et por la libra de la plegadura granada...» (págs. 117-118, § 28).

pua

«Et por el par de las espuelas doradas de pua ocho maravedís» (fol. 4v., lin. 29).

El DECH, s.v., documenta pua en Guillén de Segovia, APal., etc. y señala que «el que no pueda dar ejs. más antiguos del vocablo en castellano se explica fácilmente por el sentido algo especial del vocablo, poco apto para salir en literatura o en la documentación; en un caso así esta fecha relativamente moderna no debe tomarse como indicio de una introducción tardía en el idioma. Por lo demás los testimonios abundan desde finales del s. XV». Mi intención es sólo presentar un texto que pueda servir de ejemplo a esa segura introducción más temprana de esta voz en nuestra lengua.

\section{quitoçe - quiçote}

«por fazer el jubete para arma ocho maravedís. Et sy fuere a forrar den por echar la aforradura con su quitoçe cinco maravedís» (fol. 4r., lins. 23-24).

Indudablemente se trata de un lapsus del escribano en lugar de la forma quiçote, que es la que aparece en los otros documentos de estas Cortes.

El DECH, s.v. quizote remite a marión y s.v. da una cita de Gonzalo Correas (1627): «el quizote y el marón por agosto pierden sazón (entiende que son pescados)», aunque no conozco - añade Corominas- un pez llamado quizote. Y no es extraño, ya que no debe tratarse de un pez, sino de una prenda de abrigo, similar a una capa o a un pellote. El mismo $D E C H$, s.v. alquicel, recoge esta forma del castellano antiguo. Dice «alquicel 'vestidura morisca a modo de capa' del ár. Kisâ 'paño de lana que tejían los beduinos' 'alquicel». Y sigue "del mismo origen son probablemente el cast. ant. queça 'capa, manta' y el cast. ant. quezote 'alquicel', y da en la nota 2 el siguiente ejemplo: «Venía toda la sierra cubierta de moros, e traían todos quezotes vermejos y las barbas y cabellos alfeñados» procedente de la Crón. de Juan II (h. 1460).

Sin embargo este término no aparece en los diccionarios medievales consultados y tampoco en los posteriores, y parece que debió sufrir la competencia de 
su casi homófono quixote, quexote, desapareciendo en favor de la otra forma árabe con artículo, alquicel.

La diferencia existente entre quexote y quezote, desde el punto de vista de la significación se observa, además, claramente en estos documentos, pues la primera aparece cuando se describen las labores de los «ferreros», mientras que la segunda (siempre con la dentoalveolar sorda) cuando se trata de prendas de tela; y el ejemplo más claro de su significado se halla en el Ordenamiento dado a Burgos: «Et a las costureras del lienço den les por tajar e coser en esta manera: por el quiçote de omme con sus pannos, doze dineros; e por cofias e aluanegas... et por los quiçotes que son a fechura de pellotes, et por las quiças de los ganbaxes, por cada una de estas, dos mrs.» (Cortes, II, pág. 120, §36), de donde parece deducirse que existían distintas formas de esta prenda.

C. Bernis Madrazo, sin embargo, recoge el término quixote también como prenda de vestir: «En la segunda mitad del siglo XV, los cristianos tomaron de los moros los quixotes, que eran sayos de telas veraniegas y bordados al gusto morisco en el ruedo bajo y en la delantera» ${ }^{30}$.

\section{Redondel}

«Et por la saya de la muger dos maravedís. Et por el redondel con su capirote dos maravedís (fol. 4r., lins. 14-15). Et por los redondeles de los perlados por cada vno otros ocho maravedís» (fol. 4r., lins. 16-17).

Con la misma significación que aparece en el $D R A E$, s.v. redondel 2: «Especie de capa sin capilla y redonda por la parte inferior».

El DECH, s.v. redondo documenta redondel en los Fueros Aragoneses de 1369 (V. Rom. X, 198), en cuyo estudio Pottier lo define como «sorte de cape». Sin embargo que el término, con este mismo significado, es también usual en Castilla, lo prueba no sólo este texto y los otros de Cortes coetáneos en los que también aparece, sino también el ejemplo que del mismo $D E C H$ se puede sacar, procedente de las Cortes de Burgos de 1338 (R.F.E. VIII, 349), s.v. tabardo «ninguno no traya tabardo nin rredondel d'escarlata vermeja salvo nos (el Rey)».

Sin embargo el término no lo recoge APal., ni Nebrija, ni Covarr., ni tampoco Autoridades.

\section{rodete}

«Et por el par de las espuelas doradas de rodete diez maravedís» (fol. 4v., lins. 29-30).

Espuelas doradas de rodete, es decir, de ruedecitas, a diferencia de las de púa. G. Tilander recoge rodete con este mismo significado en los Fueros Aragoneses de 1350. También en Invent. Arag. II, 349, de 1374, y aunque en este caso aparece rodera: «un par de espueras de rodera», Tilander señala que debe leerse rodeta. (Sin embargo, también en Cortes II, Ordenamiento de Burgos, aparece rrede- 
$r a$, pág. $119, \S 33$, por lo que quizás existiera también una variante con sufijo en-era, en vez de en -ete, -eta). Tampoco en este caso aparece el término en los vocabularios medievales (Oelsch ${ }^{31}$, Nebrija Voc. Esp.-Lat., Cejador Voc. Med.) y en los posteriores no se recoge el significado (Covarr., Autoridades, DRAE).

El $D E C H$, s.v. rodete lo documenta en el siglo XVI y Autoridades, pero no aporta significado.

El DEEH, s.v. rota, lo da como derivado castellano de rueda 'rueda'.

roperos

«Otrosy que den al mançebo de la cabanna con los roperos por su soldada al anno dos bezerros e çinquenta maravedís a cada vno (fol. 1v., lins. 26-27).

Este término sólo lo encontramos, además, en el Ordenamiento de Niebla (pág. 93, § 7). Autoridades, s.v. ropero, aparte de otras acepciones, recoge: «Entre los pastores llaman al que, como principal o capataz, cuida de la fábrica de los quesos» PRAGM. DE TASS. año 1627, f. 16. Sin embargo, tanto por su etimología como por el contexto en que aquí aparece, y los otros significados de esta misma voz, lo más probable es que existiera anteriormente con el de «zagal que hace los recados de la ropería de los pastores», tal como aparece en el DRAE, s.v. ropero 3.

El DECH lo documenta en el s. XV Ropero de Córdoba, sobrenombre de A. Montoro, S. XVII, Aut., pero sin significado.

\section{Sarmentar; sarmentadores; sarmentaderas}

«Et a los moços para sarmentar que le den a cada vno por el çiento de las gauillas...» (fol. 2v., lins. 5-6).

«e vendimiadores e vendimiaderas e sarmentadoras e sarmentaderas» (fol. 5r., lins. 20-21).

«Sarmentar» se documenta también en otros dos ordenamientos, el de Toledo (pág. 79, § 9) y el de Niebla (pág. 94, § 12).

En cuanto al segundo texto, aunque aparece «sarmentadoras» e «sarmentaderas», es lógico pensar que debería aparecer sarmentadores e sarmentaderas, tal como se hace la derivación en vendimiadores e vendimiaderas, y que se trata de un lapsus del escribano.

El DECH, s.v. sarmiento, documenta sarmentar hacia 1530 en Ant. de Guevara; sarmentador aparece sin fecha, y sarmentadera no lo documenta. Ninguno de los tres términos se registran en $A P a l$. o en Nebrija, aunque en ambos aparece sarmiento; Covarr. documenta la forma verbal sarmentar, y en Autoridades aparece además sarmentador, pero en ningún estudio hemos encontrado el femenino sarmentadera.

31 Oelschläger, V.R.B., A Medieval Spanish Word-List, University of Wisconsin, 1940 (citado Oelsch). 


\section{segurón}

Et den el segurón nueuo para llenna por tres maravedís e medio et segur nueuo para madera por siete maravedís... Et den la calça para el segurón por quinze dineros» (fol. 3v., lins. 9-12).

Se documenta además en el Ordenamiento de Niebla (pág. 96, § 26).

El término segur 'hacha' está ya documentado desde 1050 (Oelsch.). Sin embargo segurón sólo aparece recogido por la Academia, con el significado de «aument. de segur», es decir, 'hacha grande'. Pero por el contexto se puede deducir claramente - tanto por la utilidad como por los precios- que no es la forma marcada con el sufijo -ón la que precisamente indica el instrumento mayor. En este caso, como en algunos otros, cuando el sufijo se ha lexicalizado ya, pierde su valor y la diferencia aparece marcada por el género, de manera que será mayor el feminino: la segur / el segurón.

\section{socaro}

«Et echen el par de suelas de la çerrada por diez e ocho dineros et el par de las suelas dela mediana por treze dineros et el par de las de las suelas del socaro un maravedí» (fol. 3r., lins. 25-27).

Estamos ante un término cuya explicación es complicada. En el Ordenamiento de Niebla aparece en su lugar sorojo (pág. 96, § 25); en el de Toledo leemos: «et por el par delas suelas despaldar... et por el par delas suelas del longanel et dela yjada un mr. (pág. 82, § 20). Como se ve, en todos los casos se trata de las distintas partes del animal de las que procede la piel. Ahora bien, si con socaro se hace referencia a la parte más baja de las patas, se podría pensar en un posible étimo sócalo (lat. Socculus), pero plantearía un doble problema fonético: por un lado la no diptongación de la $\breve{~ b r e v e ~ t o ́ n i c a ~ l a t i n a, ~ p o r ~ o t r o ~ e l ~ c a m b i o ~ d e ~ l i ́ q u i d a s . ~}$ Para el primer cambio se podría recurrir, tal como hace Corominas para explicar el deriv. cast. choclo (DEELC, s.v. zueco)a la influencia del vasco, o al italianismo zòccolo 'zueco' (en el caso de zócalo); pero como italianismo sería demasiado temprano, pues zòccolo se documenta en esta lengua en el s. XIV ${ }^{32}$, y quedaría además el problema del cambio $l>r$. Pero socaro, al igual que yjada en el texto de Burgos, puede referirse también a la «cavidad entre las costillas falsas y los huesos de las caderas», en cuyo caso se podría pensar en la influencia del vasco zoko 'rincón' o en un derivado regresivo a partir de socareña, socarena, variantes de socarreña, socarrena, «cuyas $r r$ pueden ser primitivas», según dicen Corominas y Pascual. Estas formas además de su acepción primitiva «parte que sobresale del alero del tejado», tienen también otras acepciones secundarias, como son 'escondrijo, agujero“ (Vid. DECH, s.v. Socarrena), por lo que quizás esta hipótesis tendría más posibilidades. 
Tafe

«e con forradura de tafe o de panno rico cinco maravedís» (fol. 3v., lins. 32-33).

Término que aparece en todos los documentos de estas Cortes, así (Murcia pág. 288, § 15) o con doble -ff- (en los cuatro de Cuadernos de Cortes), se trata indudablemente de la misma voz que tafetán (procedente del persa taftah o taftaf) que se documenta en los Fueros Aragoneses de 1350. Corominas y Pascual, s.v. tafetán, señalan que esta última forma debió llegar al castellano por vía del comercio mediterraneo, desde el italiano (taffetà) y el catalán (tafetà, pl. tafetans 1397), pero no hacen ninguna referencia a la forma tafe. Tampoco en los otros estudios consultados se hace referencia alguna a esta forma, ni siquiera en el Glosario etimológico de palabras españolas de origen oriental, de Eguilaz y Yanguas. Una posible explicación a esta forma es que se trate de un caso de haplología, con adición posterior de la - $e$ paragógica, tras un final consonántico en $-f$ no aceptado en castellano en esta época. 
